\title{
Oxysterols formation: a review of a multifactorial process
}

Blanca Barriuso, Diana Ansorena*, Iciar Astiasarán

Department of Nutrition, Food Science and Physiology, Faculty of Pharmacy

University of Navarra, C/ Irunlarrea s/n, 31008. IDISNA- Instituto de Investigación Sanitaria de Navarra, Pamplona, Spain

bbarriuso@alumni.unav.es; iastiasa@unav.es

*Correspondence: email: dansorena@unav.es; telephone: 0034-948425600 (ext. 6263); Fax: +34948425649. 


\section{Highlights}

1- Heating sterols at $180^{\circ} \mathrm{C}$ produced a high extent of oxidation.

2- The presence and unsaturation degree of the surrounding lipids protected sterols from oxidation.

3- Plant aqueous extracts protected cholesterol from oxidation.

4- Greater amounts of campesterol-derived oxidation products were observed, followed by sitosterol, cholesterol and stigmasterol.

5- In 5 out of 7 of our studies, 7-keto derivatives were the most abundant oxysterols formed.

\section{Abstract}

Dietary sterols are nutritionally interesting compounds which can suffer oxidation reactions. In the case of plant sterols, they are being widely used for food enrichment due to their hypocholesterolemic properties. Besides, cholesterol and plant sterols oxidation products are associated with the development of cardiovascular and neurodegenerative diseases, among others. Therefore, the evaluation of the particular factors affecting sterol degradation and oxysterols formation in foods is of major importance. The present work summarizes the main results obtained in experiments which aimed to study four aspects in this context: the effect of the heating treatment, the unsaturation degree of the surrounding lipids, the presence of antioxidants on sterols degradation, and at last, oxides formation. The use of model systems allowed the isolation of some of these effects resulting in more accurate data. Thus, these results could be applied in real conditions.

Keywords: cholesterol, plant sterols, Sterol Oxidation Products, thermo-oxidation, antioxidants 


\section{GRAPHICAL ABSTRACT}

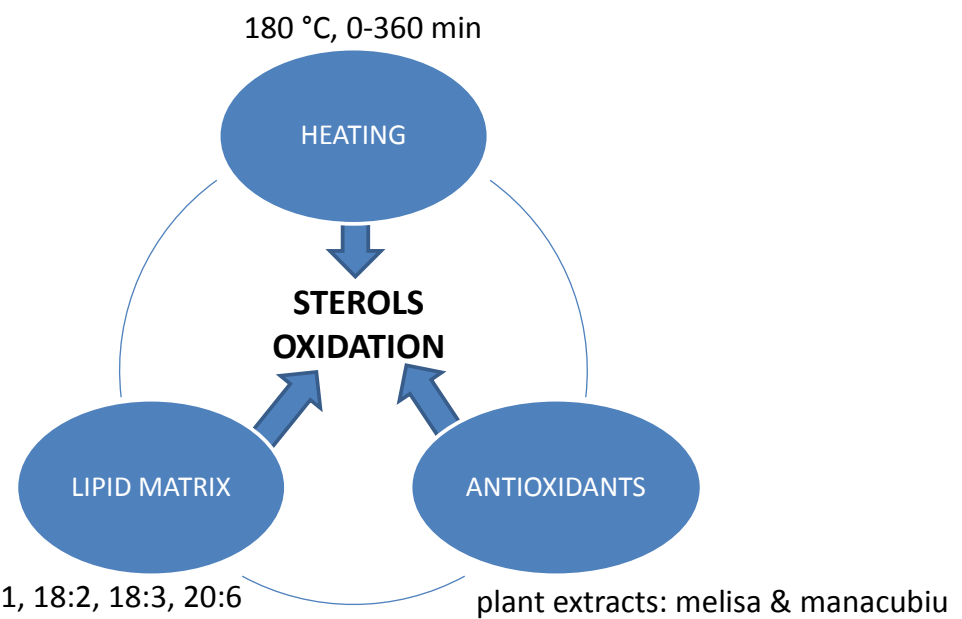




\section{Introduction}

The interest on dietary sterols and, specifically on their oxidation derivatives (SOPs- sterol oxidation products), has risen in the last years. High cholesterol intake is related to cardiovascular diseases. Moreover, its oxidation products (COPs) have been closely linked to toxicological effects (1-3). In the case of phytosterols, their beneficial effects, which are related to reductions in Low Density Lipoproteins (LDL) plasma levels (4), have promoted their incorporation into a variety of foodstuffs as functional foods (5-8). However, their presence in this kind of products could be threatened by oxidation reactions, which will lead to the formation of oxidation compounds. Interestingly enough, these compounds, as well as the COPs, have lately been associated with harmful effects in the organism (9-11).

In this context, there is evidence that SOPs are actually absorbed from the diet $(12,13)$. Given their potentially harmful effects on human health, a deeper study of the factors affecting the formation of dietary SOPs is essential. The content and distribution of SOPs in foods depend on food composition, industrial processing, storage conditions and culinary procedures. All these processes share several particular factors which are key elements in sterols oxidation, such as temperature, oxygen, light exposure, the lipid surrounding matrix, and presence of antioxidants and water.

Foods are usually complex matrices where interferences among different components may hamper a clear view of the mechanisms involved in sterol oxidation. Therefore, model systems are a very useful tool to separately evaluate the factors exerting influence over this process, avoiding the ambiguity which results from the interferences among them. Thus, a deeper understanding of the underlying mechanisms is enabled and kinetic curves can be easily determined. Consequently, a diversity of experimental approaches can be found, from fully modelled studies where only chemical standards are used as components of the experiments 
$(14,15)$, to intermediate model systems, where chemical standards are mixed within foods $(16-18)$.

This paper aims to evaluate the effect of different factors involved in sterols oxidation, gathering recently published data from our research group (19-25). Four different sterols were evaluated in this report focusing on the effect of the heating treatment, the unsaturation degree of the surrounding lipids and also the presence of antioxidants in sterol oxidation. Model systems and some food applications are included in the review. Detailed information on experimental conditions can be found in the original papers. Briefly, regarding the model systems, sterols were dissolved in chloroform and added to the corresponding compounds in each case (fatty acids, triglycerides or plant extracts). For plant extracts addition, and due to their hydrophilic properties, they were dissolved in methanol before mixing with the chloroform solution. Then, the sample was evaporated and heated at $180{ }^{\circ} \mathrm{C}$ during times ranging from 0 to $360 \mathrm{~min}$. Temperature of $180{ }^{\circ} \mathrm{C}$ was selected for the experimental procedure since it is common in cooking procedures and ensures full melting of sterols.

\section{Effect of heating treatment}

Heating is a well-known lipid oxidation inducer, since it causes the reduction of the activation energy for the hydrogen abstraction which leads to enhanced free radical formations. Thus, heat intensity and time are key factors affecting sterol oxidation. According to the results obtained in the different experimental designs, high sterol degradation and SOPs formation were observed in all the model systems analyzed. Figure 1a summarizes these findings based on the model systems containing sterols, as pure standards, without any other lipid matrix in the system.

All the experiments pointed out drastic sterols degradation already from the beginning of the heating treatment, exceeding $50 \%$ degradation after $10 \mathrm{~min}$. Cholesterol degradation was below this value in the experimental setting where higher initial amounts of cholesterol were 
placed in the tubes $(20 \mathrm{mg}$ in (21) compared to around 1-2 $\mathrm{mg}$ in the other experimental settings). As it has previously been described, higher amounts of sample hamper the heat transfer and reduce the area-to-volume ratio, slowing down the oxidation process (26).

One of the most variable experimental conditions in sterol degradation research is the heating temperature. A wide diversity of results has been noticed, even when comparing results from the same research group $(15,27,28)$. Several studies performed sterol degradation at $150{ }^{\circ} \mathrm{C}$ using cholesterol samples. These works have roughly obtained only $50 \%$ degradation after 30 $60 \mathrm{~min}$ heating, most likely due to the low temperature applied $(28,29)$. When higher temperature was applied $\left(200^{\circ} \mathrm{C}\right)$, up to $89 \%$ degradation was achieved in the first 10 minutes (30). However, at that same temperature $\left(200{ }^{\circ} \mathrm{C}\right)$, Thanh et al. (31) obtained slower phytosterol degradations than those provided by our work. Regarding experiments attained using thermo-oxidation treatments similar to ours, $\mathrm{Xu}$ et al. (30) found $61 \%$ of cholesterol degradation after $10 \mathrm{~min}$ heating at $175^{\circ} \mathrm{C}$. Nevertheless, percentages of just $50 \%$ degradation of cholesterol, $\beta$-sitosterol and stigmasterol were detected after 60 min heating in some other works $(17,32)$.

As it can be observed in Figure $1 \mathrm{~b}$, SOPs started to form right at the beginning of the heating process, reached then maximum values and started to decrease after 5 to 20 min onwards in most cases. When $20 \mathrm{mg}$ of cholesterol were initially heated, the maximum COPs value was delayed up to $30 \mathrm{~min}$, which again could be attributed to the higher amount of sample used compared to the other experimental settings. 
A) STEROLS

DEGRADATION

cholesterol

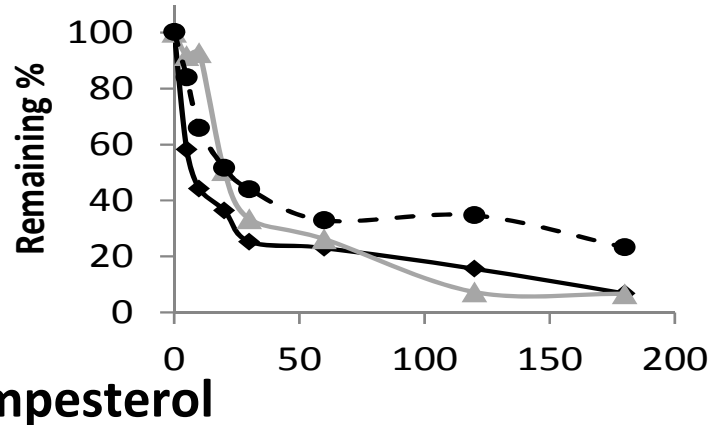

\section{campesterol}

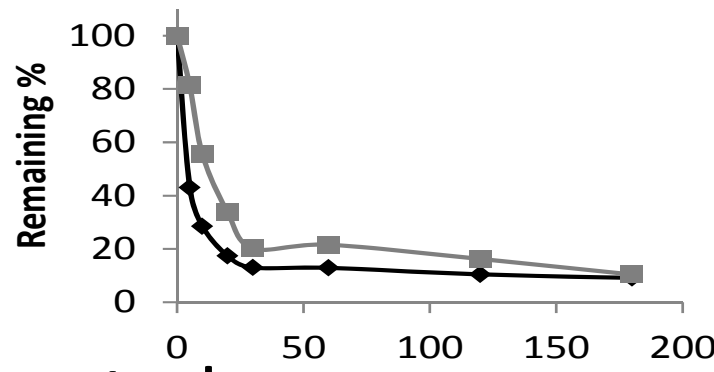

stigmasterol

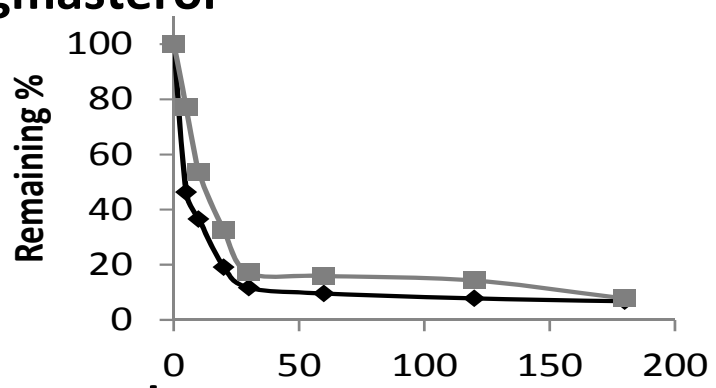

sitosterol

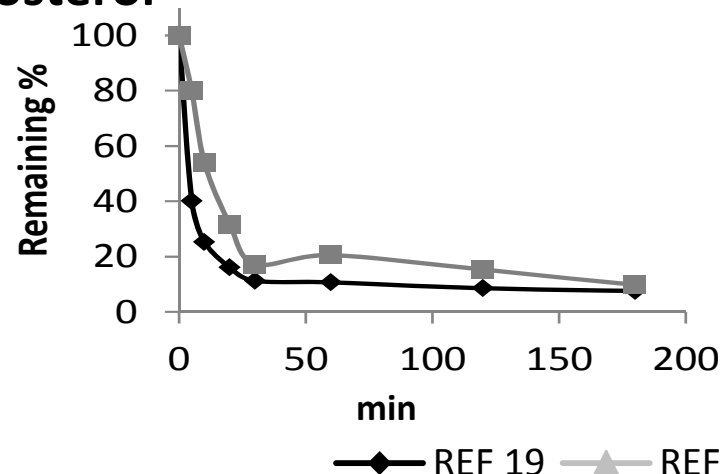

Figure 1. Sterols are degraded and oxysterols formed. A) Remaining sterol and B) oxysterol content during heating of the model system used for each sterol, in the different experimental settings.

Remaining \%= remaining sterol/initial sterol $* 100$ $\mu \mathrm{g} / \mathrm{mg}=\mu \mathrm{g}$ oxysterols / $\mathrm{mg}$ initial sterol
B) OXYSTEROLS FORMATION
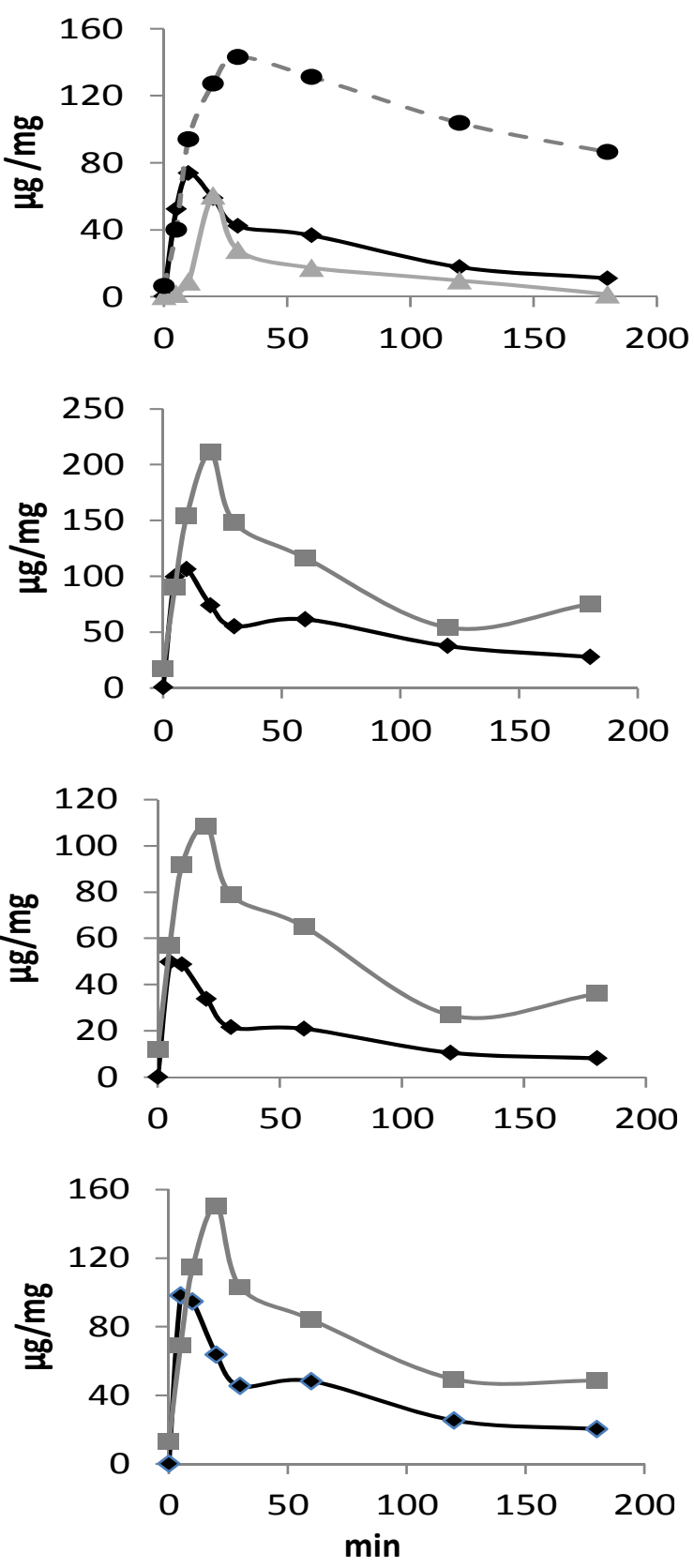

- REF 24 
Seckin and Metin (33) and Derewiaka et al. (29) concluded that the changing of processing temperatures had an important significant effect on oxycholesterols content. Yen et al. (15), Zhang et al. (34) and Chien et al. (28) did not find any decrease in oxysterol levels at $150{ }^{\circ} \mathrm{C}$ even after 60 min heating, noticing constant levels or even increasing trends up to that heating time. However, at $200{ }^{\circ} \mathrm{C}$, Zhang et al. (34) noted the drop in oxysterol much earlier (20 min). In this context, it has been hypothesized that only drastic heating treatments may induce oxysterol degradation (31), and $150^{\circ} \mathrm{C}$ may not be enough to achieve it. In this sense, Soupas et al. (35) proposed $140{ }^{\circ} \mathrm{C}$ as the key temperature in the process, since sterols behaved differently below and above this temperature. At $175-180^{\circ} \mathrm{C}$, whereas $\mathrm{Xu}$ et al. (30) found the maximum amount of COPs at similar times as in our experiment, some other works, $(14,32$, 36) obtained that SOPs decreased only after 40,60 and 90 min, respectively.

It seems that the heat treatments applied in our previous work have been more destructive than those applied in other studies, since sterols degradation percentages were higher and formation of oxysterols occurred earlier. This suggests that other experimental conditions, besides temperature and time, could have influenced the results, such as the properties of the heating slopes, the higher initial sterol amount, the area-to-volume ratios, the different evaporation procedures, and the application of filtration methods or disposal of the tubes. In reference to the incidence of light, it should be highlighted that our samples were not capped neither covered during the heating procedure, which was performed in a room with natural light. Hence, a certain development of photo-oxidation could have occurred, which could explain the observed over-oxidation.

In contrast with the sterols, oxysterols showed to rapidly increase during the first 30 minutes in all the experiments. The apex in oxysterols levels was then followed by a decrease in all of our experiments, as shown in Figure 1. This fact could be explained by the formation of further oxidized compounds after a certain moment of the heating process. These compounds may 
consist of high molecular weight compounds, such as di- and oligomers (of hydroxy, epoxy and keto derivatives) linked by ether bonds or by combining radicals (37-39). They can also consist on steradienes and steratrienes, compounds formed from sterols, 7-ketosterols or 7hydroxysterols (40). Using a model system consisting on pure stigmasterol heated at $180^{\circ} \mathrm{C}$ for 180 min, Menéndez-Carreño et al. (32), in agreement with Lampi et al. (37), reported that dimeric and polymeric products contributed to $30 \%$ of stigmasterol degradation. MenéndezCarreño's group also described a strong relationship between non-polar/mid polar and the other indicators of oxidation reactions. This evidence was also supported by the formation of oligomeric species of campesterol, sitosterol and cholesterol during heating $(29,41)$.

\section{Effect of unsaturation degree}

The role played by surrounding lipids in sterol oxidation has been under debate during the last decade. In fact, the discussion is still in vogue, since opposite results have been reported by several research groups. Whereas some authors maintain the hypothesis that there is a protective effect of the surrounding lipid matrix over the sterols susceptibility to oxidation (42), some others state that it is the high unsaturation of this matrix what promotes sterol oxidation (43). Both trends are strongly supported by wide empiric evidence and powerful arguments. On the one hand, lipids can compete for oxygen with sterols and reduce the oxidation of the latters by selfoxidation. This way, unsaturated lipids would be more efficient than saturated ones in protecting sterols, because their double bonds enhance their likelihood to oxidation. On the other hand, radicals and oxygenated species derived from lipid oxidation can exert a pro-oxidant effect towards sterols. A balance between both mechanisms is the most probable situation. Therefore, the experimental conditions can displace the balance to one or other side.

In our studies, the effect of the presence of different surrounding lipids against sterols oxidation was analysed $(20,22,24,25)$. They were tested under different chemical forms: 
18:0, 18:1, 18:2, and 18:3, as fatty acids methyl esters (FAME), triacylglycerides (TAG) standards, or within natural TAG from vegetable oils. In addition, free docosahexaenoic acid (DHA) was also tested. In general, the presence of lipids was protective against sterols oxidation; only in the case of cholesterol + free DHA model system showed an oxidative promoting effect by the fatty acids. The other lipid matrices (stearate, oleate, linoleate, linolenate and their TAG) inhibited both sterol degradation and SOPs formation.

In addition, we also tried to statistically describe sterol degradation during thermal treatment. Regression curves were built for every case (Table 1), obtaining kinetic models, whose $k$ values can give an idea of the intensity and rate of sterol degradation: the higher the $k$ value, the faster the sterol degradation occurs. According to the different experimental settings, $k$ values obtained for isolated sterols were greater in comparison with any lipid medium. Furthermore, almost identical $k$ values were observed for stigmasterol within linoleate and within sunflower oil (containing more than $60 \%$ linoleic acid). Among the different lipid matrices, the more unsaturated ones produced lower $k$ values for sterols degradation, except for DHA. This denoted slower sterols degradation in the presence of lipids of increasing unsaturation degree, according to previous explanations.

Table 1. First order kinetic model corresponding to $\ln \left(\right.$ sterol $/$ sterol $\left._{0}\right)=-$ k.t. For each sterol, the first column shows the kinetic constant $(k)$ and the second one the level of adjustment $\left(R^{2}\right)$. Equations modelized sterol degradation during heating treatment.

\begin{tabular}{llllllllll}
\hline \multirow{2}{*}{ MATRIX } & \multicolumn{2}{c}{ cholesterol } & \multicolumn{2}{c}{ campesterol } & \multicolumn{2}{c}{ stigmasterol } & \multicolumn{2}{l}{ sitosterol } & \multirow{2}{*}{ REFERENCE } \\
\cline { 2 - 8 } & $\boldsymbol{k}\left(\mathbf{m i n}^{-1}\right)$ & $\mathbf{R}^{2}$ & $\boldsymbol{k}\left(\mathbf{m i n}^{-1}\right)$ & $\mathbf{R}^{2}$ & $\boldsymbol{k}\left(\mathbf{m i n}^{-1}\right)$ & $\mathbf{R}^{2}$ & $\boldsymbol{k}\left(\mathbf{m i n}^{-1}\right)$ & $\mathbf{R}^{2}$ & \\
\hline Alone & 0.0435 & 0.828 & 0.1199 & 0.883 & 0.0997 & 0.925 & 0.1376 & 0.909 & 19 \\
Alone & 0.0279 & 0.945 & - & - & - & - & - & - & 20 \\
Tristearate & 0.0146 & 0.972 & - & - & - & - & - & - & 20 \\
Trioleate & 0.0090 & 0.995 & - & - & - & - & - & - & 20 \\
Trilinoleate & 0.0064 & 0.891 & - & - & - & - & - & - & 20 \\
Trilinolenate & 0.0056 & 0.866 & - & - & - & - & - & - & 20 \\
Alone & - & - & 0.0500 & 0.906 & 0.0553 & 0.943 & 0.0543 & 0.917 & 24 \\
Stearate & - & - & 0.0237 & 0.980 & 0.0261 & 0.983 & 0.0253 & 0.980 & 24 \\
Oleate & - & - & 0.0076 & 0.980 & 0.0078 & 0.980 & 0.0081 & 0.961 & 24 \\
Linoleate & - & - & 0.0046 & 0.918 & 0.0048 & 0.885 & 0.0042 & 0.865 & 24 \\
Linolenate & - & - & 0.0047 & 0.952 & 0.0049 & 0.947 & 0.0049 & 0.952 & 24 \\
Sunflower oil & 0.0044 & 0.927 & - & - & 0.0050 & 0.878 & - & - & 22 \\
\hline
\end{tabular}


As it has been previously discussed, a variety of results has been reported in respect to this issue. However, not all of them are in accordance with the present data. In an attempt to understand the causes of those differences, several hypotheses are suggested.

The type of interaction between the surrounding lipids and the sterols may be a key factor in the oxidation process, as well as the ratio sterol: lipid used. When sterols are esterified with fatty acids, the oxidation is promoted since the generated radicals are in close contact with the sterol oxidation sites. Hence, the more unsaturated the fatty acids are, the more sterol oxidation is achieved (43-44).

Nevertheless, free sterol, meaning not linked to the fatty acids, present a weaker, interaction with the lipid matrix. In these cases, the effect of the competition for oxygen by the lipids would be predominant. Moreover, increasing the unsaturation degree would imply a reduction in sterol oxidation $(14,42,45)$. However, when double bonds are in high numbers, lipid susceptibility to oxidation is extremely high. Then, it is quickly degraded allowing the promotion of sterols oxidation by the large amount of generated pro-oxidant species. However, this promotion hampers the protection against sterols oxidation. This would be the case of the current work (Table 1), where free sterols are protected from oxidation in the presence of saturated (stearic) and $18 \mathrm{C}$ unsaturated lipids (oleic, linoleic and linolenic acids or their methyl esters), but not in the presence of highly unsaturated lipids (DHA).

Different routes of oxidation could also contribute to the divergence of the results. In this sense, some of works consider photo-oxidation at room temperature during several days, and some others induced oxidation by heat application. Among the thermo-oxidative experiments, different temperatures have been used. This factor has been shown to be critical in the protective/promoting effects of the lipids towards sterol oxidation (35). At the high temperature of our experimental settings $\left(180^{\circ} \mathrm{C}\right)$, our systems were at liquid phase in all 
cases, which allowed a better solution of the sterols. This produced a certain stearic hindrance around them, which hindered the access of oxygen, slowing down the oxidation rate.

Mathematical modelling appears to be very useful for sterol degradation studies, since it enables easy comparison of data from different experimental settings. Several authors have performed sterols kinetic studies (46), most of them using elegant approaches and complex mathematical calculations. Chien et al. (27) found cholesterol degradation and oxysterols formation to follow first order and second order reactions and calculated the corresponding equations. Their work, as well as others, efficiently contributed to elucidate the mechanisms by which sterol oxidation occurs. But for studies aiming to compare oxidative trends and general behaviors towards heating or storage, it is very useful, and easily approachable, to fit a trend curve, as we made in our works. To our knowledge, few authors give the mathematical fit of their sterol degradation curves, probably due to insufficient experimental data along time. Most of these studies show no more than 3 or 4 heating points $(14,29,37,47)$. The evaluation of 7-9 points, as made in our experimental conditions, enables obtaining useful information to build reliable regression curves.

\section{Effect of antioxidants presence}

Plant foods are rich in compounds with antioxidant properties. Among them, the most outstanding are vegetable oils, fresh fruits and fruit and seeds beverages, such as wine, tea and coffee. These natural antioxidant properties have been extensively reported to protect against lipid oxidation within foods, mainly during processing, cooking and storage $(17,48-50)$. Particular antioxidant compounds have been associated with these properties, mainly tocopherols, carotenoids and phenolic compounds.

Nowadays, the consumer's interest towards natural products has promoted the research on plant extracts due to their addition into foodstuffs (51-53). We selected two promising species for their potential use against cholesterol oxidation: Melissa officinalis (melisa) and Solanum 
sessiliflorum (mana-cubiu) considering their antioxidant properties. The results obtained in the different experiments performed are summarized in Table 2.

Table 2. Effect of the presence of melisa and mana-cubiu aqueous extracts on cholesterol degradation and COPs formation.

\begin{tabular}{lllllc}
\hline Antioxidant & System & Dose & $\begin{array}{l}\text { Cholesterol } \\
\text { degradation }\end{array}$ & $\begin{array}{l}\text { COPs } \\
\text { formation }\end{array}$ & Reference \\
\hline M.officinalis extract & Cholesterol & $2 \mathrm{~g} / 100 \mathrm{~g}$ chol & $82 \%$ inh $^{1}$ & $94 \%$ inh $^{1}$ & 21 \\
M.officinalis extract & Beef patty & $150 \mu \mathrm{g} / \mathrm{g}$ patty & No effect & No effect & 21 \\
S.sessiliflorum extract & Cholesterol & $1 \mathrm{~g} / 2 \mathrm{~g} \mathrm{chol}$ & $59 \%$ inh $^{2}$ & $89 \%$ inh $^{2}$ & 25 \\
S.sessiliflorum extract & Tuna patty & $5000 \mu \mathrm{g} / \mathrm{g}^{2}$ patty & No effect & No effect & 23 \\
\hline
\end{tabular}

${ }^{1}$ Results after $10 \mathrm{~min}$ of heating treatment; ${ }^{2}$ Results after $10 \mathrm{~min}$ of heating treatment; inh (inhibition); COPs (cholesterol oxidation products)

As it can be observed, their aqueous extracts were strongly effective in isolated model systems containing only cholesterol. They drastically reduced cholesterol degradation and COPs formation. M. officinalis and S. sessiliflorum extracts were rich in phenolic acids, rosmarinic (123 mg/g) and $5 \alpha$-caffeoylquinic acid $(2.48 \mathrm{mg} / \mathrm{g})$, respectively. Thus, the antioxidant capacity was attributed to the presence of these compounds in the aqueous extracts. In this sense, Kmiecik et al. (54) recently hypothesized about the stronger efficiency on cholesterol oxidation of phenolic acids compared to other phenolic compounds.

However, when tested in food systems, we found that phenolic acids were not that effective within beef or tuna patties. In beef patties, sensory aspects limited the acceptable dose of melisa to $65 \mu \mathrm{g} / \mathrm{g}$ in the non-emulsion containing patties and to $150 \mu \mathrm{g} / \mathrm{g}$ in the emulsioncontaining ones. In these conditions, melisa was not effective in controlling sterol oxidation. In tuna patties, although a much higher concentration of mana-cubiu extract could be added $(5000 \mu \mathrm{g} / \mathrm{g})$, its antioxidant effect was probably devoted to other lipids within tuna, whose polyunsaturated fatty acids are easily oxidized. In this sense, when a pure DHA standard was heated in the presence of mana-cubiu, it degraded to a lesser extent than without the extract, 
but there was no improvement on cholesterol oxidation. Thus, mana-cubiu exhibited an antioxidant effect towards DHA and not towards cholesterol, which would support the abovementioned hypothesis. Moreover, hexanal formation (a marker of fatty acids oxidation) in tuna patties was drastically reduced in the presence of mana-cubiu, confirming its antioxidant effect over fatty acids.

When aiming to reduce COPs formation, the addition of antioxidant extracts to meat or fish patties should always take into account the sensory aspects, since their off-flavors commonly impair the applicable dose $(52,55,56)$. This is of utmost importance in foodstuffs with few or no spices in their formulation, such as beef patties. If the extract flavour is not a limiting factor and high doses can be added to the foodstuff, then the properties of the product should be considered, such as its lipid profile. Foods rich in polyunsaturated fatty acids will require higher doses of antioxidant extracts. It is then likely that the antioxidant effect would be consumed by those fatty acids, lowering the effect towards cholesterol oxidation. Studies where the antioxidant efficiency has been demonstrated in polyunsaturated matrices are numerous, and the efficiency is usually higher towards these compounds than towards cholesterol $(55,57)$. Besides, when aiming to reduce COPs formation, antioxidant extracts have been mostly applied to moderately unsaturated foods, rather than highly unsaturated ones $(49,58)$. Other compounds, such as $\alpha$-tocopherol, have previously been reported to exert protective effects towards sterols oxidation $(17,59)$.

\section{Effect of the type of sterol}

All sterols present a very similar chemical structure, only differing in the side chain. This high similarity implies a likely similar oxidative behavior. To tackle this question, a comparison among the oxidation patterns of cholesterol, campesterol, stigmasterol and sitosterol heated within sunflower, TAG, FAME or without any surroundings was carried out. 
As we have previously observed (Fig 1), the four studied sterols showed similar degradation patterns among them. This similar degradation pattern accounts for their similar dissociation enthalpies in the sterol ring (60).

In contrast, SOPs presented some differences in their formation rate depending on their original sterol. Results from the different experimental settings are compiled in Table 3. As it can be observed, the behavior is uniform among the different experimental settings. Campesterol presents the highest oxidation rate, expressed as $\mu \mathrm{g} \mathrm{SOP} / \mathrm{mg}$ initial sterol, regardless the initial ratio within the mixture of sterols. After campesterol, cholesterol and sitosterol follow, being stigmasterol the least prone to oxidation.

Table 3. Oxidation rate ( $\mu \mathrm{g}$ SOPs/mg initial sterol) of the four sterols within the different experimental settings, in decreasing order.

\begin{tabular}{llc}
\hline \multicolumn{1}{c}{ MATRIX } & Oxidation rate $(\boldsymbol{\mu g}$ SOPs $/$ mg initial sterol) & REFERENCE \\
\hline Alone & campesterol > sitosterol > cholesterol > stigmasterol & 19 \\
Sunflower oil & cholesterol > stigmasterol & 22 \\
Alone & campesterol > sitosterol > stigmasterol & 24 \\
Stearate & campesterol > sitosterol > stigmasterol & 24 \\
Oleate & campesterol > sitosterol > stigmasterol & 24 \\
Linoleate & campesterol > sitosterol > stigmasterol & 24 \\
Linolenate & campesterol > sitosterol > stigmasterol & 24 \\
\hline
\end{tabular}

SOPs: Sterol Oxidation Products

Campesterol has previously been reported to yield more SOPs than other sterols $(8,54,61)$. González-Larena et al. (61), postulated that the different surface activity of sterols could be behind this behavior, based on the results of Cercaci et al. (62). According to that work, differences in the surface activity of the sterols could influence their susceptibility to oxidation, since the higher the surface activity, the better the location of sterols in the oil-water interfaces. Thus, in our work, campesterol, due to its estimated surface activity higher than sitosterol, would locate on the interfaces of the medium, where higher contact with prooxidants is possible. However, this hypothesis would not support our data on relative oxidability of cholesterol and stigmasterol since their calculated surface activity is higher than 
that of campesterol and sitosterol, whilst they yield less SOPs amounts, as it has previously been reported (32).

This behaviour could be attributed to lower efficiency in the oxidation reaction or slower kinetics. Besides, instead of the ones we analyzed, other oxides could have been formed, such as 6-hydroxy, 20-hydroxy, 22-hydroxy, dienes, trienes... $(29,36,63)$. Moreover, SOPs derived from cholesterol and stigmasterol could have decomposed to form oligomers, polymers and other compounds characteristic of advanced stages of oxidation $(29,39)$, yielding an overall lower balance than for campesterol and sitosterol derived oxides.

Furthermore, we used different relative initial amounts of sterols within each experimental setting, which could also explain the different oxidation rate, as thermo-oxidation is significantly dependent on the sample area-to-volume ratio (26). In this sense, low amounts of sterols would be overexposed to oxygen since particles present a high area-to-volume ratio, showing a greater exhibition to pro-oxidation agents. Nevertheless, according to Cercaci et al. (62), higher sterol concentration would favour their presence at the interfaces and promote oxidation, contrary as the results obtained in the current work.

Regarding stigmasterol, the double bond present in C22 could lead to the idea of a greater oxidation of this compound, however, these bonds in the side chain do not affect its reactivity $(60,64)$. Therefore, it is not surprising that, in this work, stigmasterol was the less oxidized sterol.

Some authors (65) have recently attributed the different experimental conditions applied to sterols oxidation susceptibility.

As it has been reported, the absorption of campesterol (and its oxides) is higher than that of sitosterol (and its oxides)(12, 66 ). Nevertheless, oxysitosterol plasma levels are usually higher than campesterols levels, probably due to in vivo oxidation of sterols (67). Considering the higher campesterol oxidation rate compared to sitosterol, as reported in our work, higher 
potential toxicity of campesterol-enriched foods could be hypothesized. In this regard, the European legislation establishes lower limits for campesterol addition to functional foods than for sitosterol ( $<40$ and $<80 \%$ of the sterols addition, respectively) (68).

\section{Distribution of particular oxysterols}

Seven different oxysterols derived from the four sterols analyzed were analyzed: $7 \alpha-$

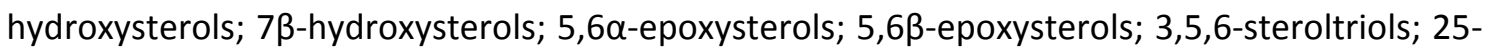
hydroxysterols and 7-ketosterols. Table 4 summarizes the relative oxysterols distribution, excluding 25-hydroxysterol, at the moment of their maximum concentration for each experiment.

Table 4. Oxysterols distribution(derived from the four studied sterols) found at the moment of their maximum concentration in the different matrices, including the prevalence of alpha/beta epimer of 7-hydroxy and 5,6-epoxy derivatives.

\begin{tabular}{llc}
\hline MATRIX & distribution & REFERENCE \\
\hline Alone & $7-\mathrm{K}>7-\mathrm{H}>5,6-\mathrm{E}>$ triol & 19 \\
Alone & $7-\mathrm{K}>5,6-\mathrm{E}>7-\mathrm{H}>$ triol & 21 \\
Alone & $7-\mathrm{K}>7-\mathrm{H}>5,6-\mathrm{E}>$ triol & 20 \\
Tristearate & $7-\mathrm{K}>5,6-\mathrm{E}>7-\mathrm{H}>$ triol & 20 \\
Trioleate & $7-\mathrm{K}>7-\mathrm{H}>5,6-\mathrm{E}>$ triol & 20 \\
Trilinoleate & $7-\mathrm{K}>7-\mathrm{H}>5,6-\mathrm{E}>$ triol & 20 \\
Trilinolenate & $7-\mathrm{K}>7-\mathrm{H}>5,6-\mathrm{E}>$ triol & 20 \\
Beef patty & $7-\mathrm{K}>5,6-\mathrm{E}>7-\mathrm{H}>$ triol & 21 \\
Alone & $7-\mathrm{K}>5,6-\mathrm{E}>7-\mathrm{H}$ & 25 \\
Tuna patty & $7-\mathrm{H}>7-\mathrm{K}>5,6-\mathrm{E}$ & 23 \\
Sunflower oil & $7-\mathrm{H}>5,6-\mathrm{E}>7-\mathrm{K}>$ triol & 22 \\
Alone & $7-\mathrm{K}>5,6-\mathrm{E}>7-\mathrm{H}>$ triol & 24 \\
Stearate & $7-\mathrm{K}>5,6-\mathrm{E}>7-\mathrm{H}>$ triol & 24 \\
Oleate & $7-\mathrm{K}>5,6-\mathrm{E}>7-\mathrm{H}>$ triol & 24 \\
Linoleate & $7-\mathrm{K}>5,6-\mathrm{E}>7-\mathrm{H}>$ triol & 24 \\
Linolenate & $7-\mathrm{K}>7-\mathrm{H}>5,6-\mathrm{E}>$ triol & 24 \\
\hline
\end{tabular}

7-K: 7-keto derivatives; 5,6-E: 5,6-epoxy derivatives; 7-H: hydroxyl derivatives

Among the different oxysterols, 7-keto derivatives were usually the most abundant ones, except for sunflower and tuna matrices. 7-ketosterols are commonly found as the main oxysterols both in model and food systems $(14,29)$. These compounds are moderately stable, 
being formed either directly from hydroperoxides or through 7-hydroxysterols dehydration (69). Moreover, they are frequently the end molecules of the oxidation route. Hence, they have extensively been reported as good sterols oxidation markers (70).

Nevertheless, in the case of sunflower and tuna matrices, 7-hydroxy and 5,6-epoxy were the major compounds found. Given the different possible formation routes for these compounds, several hypotheses were proposed. First, the formation of 7-hydroxycholesterol could have been catalyzed by specific enzymes present in tuna. Second, the direct bimolecular addition of oxygen to the sterol double bond could have been favoured over the radical formation mechanism. This second hypothesis could be the result of the complex environmental feature of the sunflower oil, yielding higher 5,6-epoxy amounts.

A third hypothesis would involve photo-oxidation processes, which would enhance 7hydroxysterols formation. Furthermore, the higher levels of 7-hydroxysterols found could indicate that first stages of oxidation are still ongoing, therefore, only low amounts of 7-keto would have been formed from them at that time. In addition, this last hypothesis is further supported by some works which reported this type of distribution profile for oxysterols (54Kmiecik et al., 2015; 61González-Larena et al., 2015).

At last, Triol and 25-hydroxy derivatives were, by far, the less abundant oxysterols. The low levels of triols found were expected since their formation from epoxides is favoured in aqueous acidic media $(32,69)$. As for the side-chain derivatives, 25 -hydroxycholesterol was detected in small amounts only after long heating times, probably due to the lack of specific enzymes in the analyzed samples. They were not found among plant sterols' oxides, neither by other authors (71).

\section{Conclusion}

Sterols' thermo-oxidation is a multifactorial process which strongly depends on timetemperature combination, producing high sterol oxidation from the beginning of the process. 
The presence of the lipid matrix in addition to its unsaturation degree, as well as the presence of phenolic compounds with antioxidant activity, significantly protected sterols from oxidation in model systems. The inclusion of plant extracts in foodstuffs to achieve this goal, appeared to be promising when sensory aspects and sample characteristics are taken into account.

We thank the Spanish Ministry of Economy and Competitiveness (AGL2014-52636-P) and Red de Excelencia Consolider PROCARSE (AGL2014-51742-REDC) for the financial support.

\section{References}

1. Otaegui-Arrazola, A., Menéndez-Carreño, M., Ansorena, D., Astiasarán, I. (2010). Oxysterols: A world to explore. Food and Chemical Toxicology, 48(12), 3289-3303.

2. Zarrouk, A., Vejux, A., Mackrill, J., O'Callaghan, Y., Hammami, M., O’Brien, N., \& Lizard, G. (2014). Involvement of oxysterols in age-related diseases and ageing processes. Ageing Research Reviews, 18, 148-162.

3. Weingärtner, O., Husche, C., Schött, H. F., Speer, T., Böhm, M., Miller, C. M., McCarthy, F., Plat, J., Lütjohann, D., \& Laufs, U. (2015). Vascular effects of oxysterols and oxyphytosterols in apoE -/- mice. Atherosclerosis, 240(1), 73-79.

4. Demonty, I., Ras, R. T., van, d. K., Duchateau, G. S. M. J. E., Meijer, L., Zock, P. L., Geleijnse, J. M., \& Trautwein, E. A. (2009). Continuous Dose-Response Relationship of the LDL-Cholesterol Lowering Effect of Phytosterol Intake. The Journal of nutrition, 139(2), 271-284.

5. Kuhlmann, K., Lindtner, O., Bauch, A., Ritter, G., Woerner, B., Lindtner, O., Bauch, A., Ritter, G., Woerner, B., \& Niemann, B. (2005). Simulation of prospective phytosterol intake in Germany by novel functional foods. British journal of nutrition, 93(3), 377-385.

6. Ozer, B., \& Kirmaci, H. (2010). Functional milks and dairy beverages. International Journal of Dairy Technology, 63(1), 1-15.

7. Alemany-Costa, L., Gonzalez-Larena, M., Garcia-Llatas, G., Alegria, A., \& Barbera, R. (2012). Sterol stability in functional fruit beverages enriched with different plant sterol sources. Food Research International, 48(1), 265-270.

8. Botelho, P. B., Galasso, M., Dias, V., Mandrioli, M., Lobato, L. P., Rodriguez-Estrada, M. T., \& Castro, I. A. (2014). Oxidative stability of functional phytosterol-enriched dark chocolate. LWT Food Science and Technology, 55(2), 444-451.

9. Alemany, L., Barbera, R., Alegría, A., \& Laparra, J. M. (2014). Plant sterols from foods in inflammation and risk of cardiovascular disease: A real threat? Food and Chemical Toxicology, 69(0), 140-149.

10. O'Callaghan, Y., McCarthy, F. O., \& O'Brien, N. M. (2014). Recent advances in Phytosterol Oxidation Products. Biochemical and biophysical research communications, 446(3), 786-791. 
11. Vanmierlo, T., Husche, C., Schött, H. F., Pettersson, H., \& Lütjohann, D. (2013). Plant sterol oxidation products - Analogs to cholesterol oxidation products from plant origin? Biochimie, 95(3), 464-472.

12. Tomoyori, H., Kawata, Y., Higuchi, T., Ichi, I., Sato, H., \& Sato, M. (2004). Phytosterol oxidation products are absorbed in the intestinal lymphatics in rats but do not accelerate atherosclerosis in apolipoprotein E-deficient (vol 134, pg 1690, 2004). The Journal of Nutrition, 134(10), 2738-2738.

13. Soto-Rodríguez, I., Campillo-Velazquez, P., Alexander-Aguilera, A., Rodríguez-Estrada, M. T., Lercker, G., \& Garcia, H. (2009). Biochemical and histopathological effects of dietary oxidized cholesterol in rats. Journal of Applied Toxicology, 29(8), 715-723.

14. Xu, G. H., Sun, J. L., Liang, Y. T., Yang, C., \& Chen, Z. Y. (2011). Interaction of fatty acids with oxidation of cholesterol and beta-sitosterol. Food Chemistry, 124(1), 162-170.

15. Yen, T., Inbaraj, B., Chien, J., \& Chen, B. (2010). Gas chromatography-mass spectrometry determination of conjugated linoleic acids and cholesterol oxides and their stability in a model system. Analytical Biochemistry, 400(1), 130-138.

16. Rudzinska, M., Korczak, J., Gramza, A., Wasowicz, E., \& Dutta, P. C. (2004). Inhibition of stigmasterol oxidation by antioxidants in purified sunflower oil. Journal of AOAC International, 87(2), 499-504.

17. Xu, G., Guan, L., Sun, J., \& Chen, Z. (2009). Oxidation of cholesterol and beta-sitosterol and prevention by natural antioxidants. Journal of Agricultural and Food Chemistry, 57(19), 92849292.

18. Yen T. Y., Lu, Y., Inbaraj, B. S., \& Chen, B. (2011). Cholesterol oxidation in lard as affected by CLA during heating - a kinetic approach. European Journal of Lipid Science and Technology, $113(2), 214-223$.

19. Barriuso, B., Otaegui-Arrazola, A., Menendez-Carreño, M., Astiasarán, I., Ansorena, D., (2012). Sterols heating: degradation and formation of their ring-structure polar oxidation products. Food Chemistry, 135(2), 706-12.

20. Ansorena, D., Barriuso, B., Cardenia, V., Astiasaran, I., Lercker, G., \& Rodriguez-Estrada, M. (2013). Thermo-oxidation of cholesterol: Effect of the unsaturation degree of the lipid matrix. Food Chemistry, 141(3), 2757-64.

21. Barriuso, B., Ansorena, D., Calvo, M. I., Cavero, R. Y., \& Astiasarán, I. (2015a). Role of Melissa officinalis in cholesterol oxidation: Antioxidant effect in model systems and application in beef patties. Food Research International, 69(0), 133-140.

22. Barriuso, B., Ansorena, D., Poyato, C., \& Astiasarán, I. (2015b). Cholesterol and stigmasterol within a sunflower oil matrix: Thermal degradation and oxysterols formation. Steroids, 99, 155-160.

23. Barriuso, B., Mariutti, L.R.B., Ansorena, D., Astiasarán, I., \& Bragagnolo, N. (2015c). Protective effect of a Solanum Sessiliflorum (Mana-cubiu) extract in tuna patties. VIII Jornadas de Investigación en Ciencias Experimentales y de la Salud, Pamplona, Spain 
24. Barriuso, B., Astiasarán, I., \& Ansorena, D. (2016). Unsaturated lipid matrices protect plant sterols from degradation during heating treatment. Food Chemistry, 196, 451-458.

25. Barriuso, B., Mariutti, L. R. B., Ansorena, D., Astiasarán, I., \& Bragagnolo, N. (2015d). Solanum sessiliflorum (mana-cubiu) antioxidant protective effect toward cholesterol oxidation: Influence of docosahexaenoic acid. European Journal of Lipid Science and Technology, 117

26. Lampi, A., Juntunen, L., Toivo, J., \& Piironen, V. (2002). Determination of thermo-oxidation products of plant sterols. Journal of chromatography.B, 777(1-2), 83-92.

27. Chien, J., Wang, H., \& Chen, B. (1998). Kinetic model of the cholesterol oxidation during heating. Journal of Agricultural and Food Chemistry, 46(7), 2572-2577.

28. Chien, J. T., Hsu, D. J., \& Chen, B. H. (2006). Kinetic model for studying the effect of quercetin on cholesterol oxidation during heating. Journal of Agricultural and Food Chemistry, 54(4), 1486-1492.

29. Derewiaka, D., \& Molińska (née Sosińska), E. (2015). Cholesterol transformations during heat treatment. Food Chemistry, 171(0), 233-240.

30. Xu, Z. M., Zhang, T., Prinyawiwatkul, W., \& Godber, J. S. (2005). Capabilities of different cooking oils in prevention of cholesterol oxidation during heating. Journal of the American Oil Chemists Society, 82(4), 243-248.

31. Thanh, T. T., Vergnes, M. F., Kaloustian, J., El-Moselhy, T. F., Amiot-Carlin, M. J., \& Portugal, H. (2006). Effect of storage and heating on phytosterol concentrations in vegetable oils determined by GC/MS. Journal of the Science of Food and Agriculture, 86(2), 220-225.

32. Menéndez-Carreño, M., Ansorena, D., Astiasarán, I., Piironen, V., \& Lampi, A. (2010). Determination of non-polar and mid-polar monomeric oxidation products of stigmasterol during thermo-oxidation. Food Chemistry, 122(1), 277-284.

33. Seckin, A. K., \& Metin, M. (2005). The effect of process temperature and time on the occurrence of the products of cholesterol oxidation in butter. International Journal of Food Science and Technology, 40(8), 903-906.

34. Zhang, X., Julien-David, D., Miesch, M., Geoffroy, P., Raul, F., Roussi, S., Aoude-Werner, D., \& Marchioni, E. (2005). Identification and quantitative analysis of beta-sitosterol oxides in vegetable oils by capillary gas chromatography-mass spectrometry. Steroids, 70(13), 896-906.

35. Soupas, L., Juntunen, L., Lampi, A. M., \& Piironen, V. (2004). Effects of sterol structure, temperature, and lipid medium on phytosterol oxidation. Journal of Agricultural and Food Chemistry, 52(21), 6485-6491.

36. Kemmo, S., Soupas, L., Lampi, A. M., \& Piironen, V. (2005). Formation and decomposition of stigmasterol hydroperoxides and secondary oxidation products during thermooxidation. European Journal of Lipid Science and Technology, 107(11), 805-814.

37. Lampi, A., Kemmo, S., Makela, A., Heikkinen, S., \& Piironen, V. (2009). Distribution of monomeric, dimeric and polymeric products of stigmasterol during thermo-oxidation. European Journal of Lipid Science and Technology, 111(10), 1027-1034. 
38. Struijs, K., Lampi, A., Ollilainen, V., \& Piironen, V. (2010). Dimer formation during the thermo-oxidation of stigmasterol. European Food Research and Technology, 231(6), 853-863.

39. Sosińska, E., Przybylski, R., Aladedunye, F., \& Hazendonk, P. (2014). Spectroscopic characterisation of dimeric oxidation products of phytosterols. Food Chemistry, 151(0), 404414.

40. Bortolomeazzi, R., De Zan, M., Pizzale, L., Conte, L., \& Conte, L. S. (2000). Identification of new steroidal hydrocarbons in refined oils and the role of hydroxy sterols as possible precursors. Journal of Agricultural and Food Chemistry, 48(4), 1101-1105.

41. Rudzinska, M., Przybylski, R., Zhao, Y., \& Curtis, J. (2010). Sitosterol Thermo-oxidative Degradation Leads to the Formation of Dimers, Trimers and Oligomers: A Study Using Combined Size Exclusion Chromatography/Mass Spectrometry. Lipids, 45(6), 549-558.

42. Chien, J., Lu, Y., Hu, P., \& Chen, B. (2003). Cholesterol photooxidation as affected by combination of riboflavin and fatty acid methyl esters. Food Chemistry, 81(3), 421-431.

43. Lehtonen, M., Lampi, A., Riuttamaki, M., \& Piironen, V. (2012). Oxidation reactions of steryl esters in a saturated lipid matrix. Food Chemistry, 134(4), 2030-2039.

44. Lehtonen, M., Lampi, A., Ollilainen, V., Struijs, K., \& Piironen, V. (2011). The role of acyl moiety in the formation and reactions of steryl ester hydroperoxides. European Food Research and Technology, 233(1), 51-61.

45. Hu, P. C., \& Chen, B. (2002). Effects of riboflavin and fatty acid methyl esters on cholesterol oxidation during illumination. Journal of Agricultural and Food Chemistry, 50(12), 3572-3578.

46. Medina-Meza, I., Barnaba, C. (2013). Kinetics of Cholesterol Oxidation in Model Systems and Foods: Current Status. Food Engineering Reviews, 5(3), 171-184.

47. Rudzinska, M., Przybylski, R., \& Wasowicz, E. (2009). Products Formed During Thermooxidative Degradation of Phytosterols. Journal of the American Oil Chemists' Society, 86(7), 651-662.

48. Chen, L., Lu, Y., Chen, J., \& Chen, B. (2010). Formation and Inhibition of Cholesterol Oxidation Products in Tea-Leaf Eggs during Marinating. Journal of Agricultural and Food Chemistry, 58(19), 10467-10474.

49. Mariutti, L. R. B., Nogueira, G. C., \& Bragagnolo, N. (2011). Lipid and Cholesterol Oxidation in Chicken Meat Are Inhibited by Sage but Not by Garlic. Journal of Food Science, 76(6), C909c915.

50. Hernández-Becerra, J. A., Ochoa-Flores, A. A., Valerio-Alfaro, G., Soto-Rodriguez, I., Rodríguez-Estrada, M. T., \& García, H. S. (2014). Cholesterol oxidation and astaxanthin degradation in shrimp during sun drying and storage. Food Chemistry, 145(0), 832-839.

51. Devatkal, S. K., Narsaiah, K., \& Borah, A. (2010). Anti-oxidant effect of extracts of kinnow rind, pomegranate rind and seed powders in cooked goat meat patties. Meat Science, 85(1), 155-159. 
52. Berasategi, I., Legarra, S., Garcia-Iniguez de Ciriano, M., Rehecho, S., Isabel Calvo, M., Yolanda Cavero, R., Navarro-Blasco, I., Ansorena, D., \& Astiasaran, I. (2011). "High in omega-3 fatty acids" bologna-type sausages stabilized with an aqueous-ethanol extract of Melissa officinalis. Meat Science, 88(4), 705-711.

53. Figueirêdo, B. C., Trad, I. J., Mariutti, L. R. B., \& Bragagnolo, N. (2014). Effect of annatto powder and sodium erythorbate on lipid oxidation in pork loin during frozen storage. Food Research International, 65, Part B(0), 137-143.

54. Kmiecik, D., Korczak, J., Rudzińska, M., Gramza-Michałowska, A., Hęś, M., \& KobusCisowska, J. (2015). Stabilisation of phytosterols by natural and synthetic antioxidants in high temperature conditions. Food Chemistry, 173(0), 966-971.

55. Valencia, I., O'Grady, M. N., Ansorena, D., Astiasarán, I., \& Kerry, J. P. (2008). Enhancement of the nutritional status and quality of fresh pork sausages following the addition of linseed oil, fish oil and natural antioxidants. Meat Science, 80(4), 1046-1054.

56. Karwowska, M., \& Dolatowski, Z. J. (2014). Effect of mustard on lipid oxidation in model pork meat product. European Journal of Lipid Science and Technology, 116(3), 311-318.

57. Sancho, R. A. S., de Lima, F. A., Costa, G. G., Mariutti, L. R. B., \& Bragagnolo, N. (2011). Effect of Annatto Seed and Coriander Leaves as Natural Antioxidants in Fish Meatballs during Frozen Storage. Journal of Food Science, 76(6), C838-C845.

58. Rodríguez-Carpena, J., Morcuende, D., Petron, M., \& Estevez, M. (2012). Inhibition of cholesterol oxidation products (COPs) formation in emulsified porcine patties by phenolic-rich avocado (Persea americana Mill.) extracts. Journal of Agricultural and Food Chemistry, 60(9), 2224-30.

59. Polak, T., Zlender, B., Lusnic, M., Gasperlin, L. (2011). Effects of coenzyme Q10, atocopherol and ascorbic acid on oxidation of cholesterol in chicken liver pâté. Food Science and Technology, 44 (4), 1052-1058.

60. Lengyel, J., Rimarcik, J., Vaganek, A., Fedor, J., \& Lukes, V. (2012). Oxidation of sterols: Energetics of C-H and O-H bond cleavage. Food Chemistry, 133(4), 1435-1440.

61. González-Larena, M., Garcia-Llatas, G., Clemente, G., Barberá, R., \& Lagarda, M. J. (2015). Plant sterol oxides in functional beverages: Influence of matrix and storage. Food Chemistry, 173(0), 881-889.

62. Cercaci, L., Rodriguez-Estrada, M., Lercker, G., \& Decker, E. (2007). Phytosterol oxidation in oil-in-water emulsions and bulk oil. Food Chemistry, 102(1), 161-167.

63. Bortolomeazzi, R., Cordaro, F., Pizzale, L., Conte, L., Cordaro, F., Pizzale, L., \& Conte, L. (2003). Presence of phytosterol oxides in crude vegetable oils and their fate during refining. Journal of Agricultural and Food Chemistry, 51(8), 2394-2401.

64. Kemmo, S., Ollilainen, V., Lampi, A. M., \& Piironen, V. (2008). Liquid chromatography mass spectrometry for plant sterol oxide determination in complex mixtures. European Food Research and Technology, 226(6), 1325-1334. 
65. Espinosa, R. R., Inchingolo, R., Alencar, S. M., Rodriguez-Estrada, M. T., \& Castro, I. A. (2015). Antioxidant activity of phenolic compounds added to a functional emulsion containing omega-3 fatty acids and plant sterol esters. Food Chemistry, 182, 95-104.

66. Ostlund, R. E., McGill, J. B., Zeng, C., Covey, D. F., Stearns, J., Stenson, W. F., \& Spilburg, C. A. (2002). Gastrointestinal absorption and plasma kinetics of soy delta-5-phytosterols and phytostanols in humans. American Journal of Physiology - Endocrinology and Metabolism, 282(4), E911-E916.

67. Baumgartner, S., Mensink R. P., Husche C., Lütjohann D., Plat J. Effects of plant sterol- or stanol-enriched margarine on fasting plasma oxyphytosterol concentrations in healthy subjects. Atherosclerosis, 227 (2013) 414e419

68. Official Journal of the European Union. Commission Decission 2004/336/CE

69. Iuliano, L. (2011). Pathways of cholesterol oxidation via non-enzymatic mechanisms. Chemistry and physics of lipids, 164(6), 457-468.

70. Rodríguez-Estrada, M. T., Garcia-Llatas, G., \& Lagarda, M. J. (2014). 7-Ketocholesterol as marker of cholesterol oxidation in model and food systems: When and how. Biochemical and biophysical research communications, 446(3), 792-797.

71. Oehrl, L., Hansen, A., Rohrer, C., Fenner, G., \& Boyd, L. (2001). Oxidation of phytosterols in a test food system. Journal of the American Oil Chemists' Society, 78(11), 1073-1078. 